\title{
Cardiothoracic surgery education: The times they are a changin'
}

\author{
Ryan A. Macke, MD
}

\author{
From the Department of Surgery, University of Wisconsin School of Medicine and Public Health, Madison, Wis. \\ Disclosures: Author has nothing to disclose with regard to commercial support. \\ Received for publication Nov 8, 2016; accepted for publication Nov 9, 2016; available ahead of print Dec 14 \\ 2016. \\ Address for reprints: Ryan A. Macke, MD, Department of Surgery, University of Wisconsin School of Medicine \\ and Public Health, H4/318 Clinical Sciences Center, 600 Highland Ave, Madison, WI 53792 (E-mail: macke@ \\ surgery.wisc.edu). \\ J Thorac Cardiovasc Surg 2017;153:997-8 \\ $0022-5223 / \$ 36.00$ \\ Copyright (c) 2016 by The American Association for Thoracic Surgery \\ http://dx.doi.org/10.1016/j.jtcvs.2016.11.026
}

The field of cardiothoracic surgery has undergone a dramatic evolution throughout the past half-century. We now know more, can do more, and successfully treat more disease. However, the expected mastery of this growing volume of knowledge and complex set of skills has placed an overwhelming burden on current cardiothoracic training programs and trainees. ${ }^{1}$ These challenges are further complicated by decreasing specialty exposure during general surgery residency, increasing duty-hour restrictions, and increasing limitations on resident independence. ${ }^{1,2}$ The diminishing experiential learning opportunities in training have coincided with rising American Board of Thoracic Surgery (ABTS) oral board failure rates and more residents pursuing additional training. ${ }^{2,3}$ Although the underlying cause of these trends is undoubtedly multifactorial, efforts to compensate for lost clinical experience are clearly necessary if trainees are to be adequately prepared for clinical practice.

In this issue of the Journal, Mokadam and colleagues ${ }^{4}$ present a proof-of-concept study describing their single-institution experience implementing a case-based format for their weekly educational conference. The authors did away with their previous format using a cognitive learning model consisting primarily of "traditional" lectures, instead adopting an experiential learning model focused on learner engagement and accountability with resident-driven case presentations, assessment with facultywritten quizzes, and incorporation of various forms of feedback. Resident quiz performance improved throughout the revamped 12-week curriculum. Interestingly, juniors outperformed senior residents and overall resident performance eventually exceeded that of faculty. Most residents felt the format was superior to the previous conference style and that they were more motivated to prepare. Not surprisingly, increased faculty engagement was cited by trainees as the most influential change in "flipping" of the classroom.

The authors provide a comprehensive template for programs seeking ways to adapt to the revised ABTS curricular

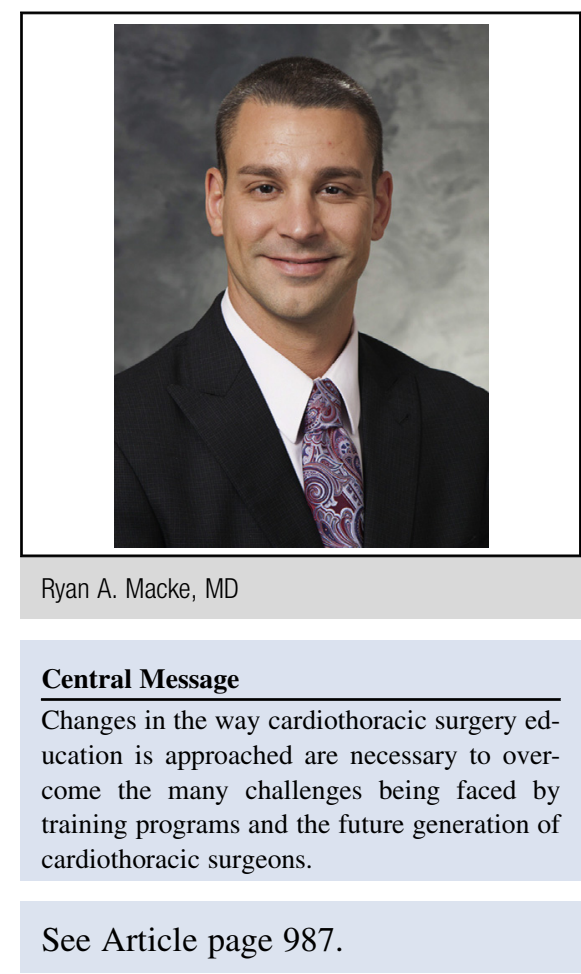

requirements, evolving thoracic surgery curriculum, and changing needs of current trainees. ${ }^{5-7}$ The choice to use an experiential learning model is just one way to address the diminishing opportunities for real-time, in-hospital learning. However, it remains unclear if the reported positive response to change was driven by the altered format itself or simply increased faculty and resident engagement. Other conference formats or learning models may be just as successful with the same degree of universal engagement.

Unfortunately, the authors provide few data on preparation time and effort put in by residents and faculty, which is an important potential barrier to adopting the proposed lecture format. As more emphasis is placed on clinical or research productivity and outcomes at academic programs, faculty education efforts have seemingly become disincentivized. ${ }^{1}$ Faculty at other programs may not be willing or able to be as engaged as the authors, who were certainly motivated to ensure the program's success. Although the study size was small, with only 10 study subjects/residents, the University of Washington program is still relatively large. It may be challenging for residents in smaller programs to dedicate the same effort with increased frequency. 
The authors should be applauded, not only for taking the initiative to change educational culture at their institution, but also for taking a scientific approach to assess its impact with prospective data collection and thoughtful analysis. However, limitations noted by the authors, such as small study population, lack of resident-level controls for comparative analysis, use of nonvalidated assessment quizzes, and lack of long-term follow-up assessing endpoints like in-service or ABTS examination results demonstrate the challenges of performing education research in the context of cardiothoracic training. Collaborative groups, such as the Thoracic Surgery Education Cooperative Group (TECoG) ${ }^{8}$ will become increasingly important to facilitate multi-institutional investigations at both traditional and integrated programs to determine the feasibility and efficacy of national education culture changes, such as the lecture format proposed by Mokadam and colleagues. ${ }^{4}$

\section{References}

1. Vaporciyan AA, Yang SC, Baker CJ, Fann JI, Verrier ED. Cardiothoracic surgery residency training: past, present and future. J Thorac Cardiovasc Surg. 2013;146: 759-67.

2. Moffatt-Bruce SD, Ross P, Williams TE. American Board of Thoracic Surgery examination: fewer graduates, more failures. J Thorac Cardiovasc Surg. 2014; 147:1464-70.

3. Odell DD, Macke RA, Tchantchaleishvili V, Loor G, Nelson JS, LaPar DJ, et al. Resident perception of technical skills education and preparation for independent practice. Ann Thorac Surg. 2015;100:2305-12.

4. Mokadam NA, Dardas TF, Hermsen JL, Pal JD, Mulligan MS, Jacobs LM, et al. Flipping the classroom: case-based learning, accountability, assessment, and feedback leads to a favorable change in culture. J Thorac Cardiovasc Surg. 2017;153:987-96.

5. Thoracic Surgery Directors Association. Thoracic surgical curriculum. Chicago: TSDA. Available at: http://www.tsda.org/education/thoracic-surgery-curricula. Accessed November 8, 2016.

6. Joint Council on Thoracic Surgery Education. Thoracic surgical curriculum. Chicago: JCTSE. Available at: http://www.jctse.org/education/thoracic-surgicalcurriculum. Accessed November 8, 2016.

7. American Board of Thoracic Surgery. Curriculum. Chicago: ABTS. Available at: https://www.abts.org/root/home/curriculum.aspx. Accessed November 8, 2016.

8. Loor G, Doud A, Nguyen TC, Antonoff MB, Morancy JD, Robich MP, et al. Development and evaluation of a three-dimensional multistation cardiovascular simulator. Ann Thorac Surg. 2016;102:62-8. 